Research Article

\title{
Continuously Frequency-Tunable Horn Filtennas Based on Dual-Post Resonators
}

\author{
Andreia A. C. Alves $\mathbb{D}^{1,},{ }^{1,2}$ Luis G. da Silva, ${ }^{1}$ Evandro C. Vilas Boas $\mathbb{D D}^{1},{ }^{1}$ Danilo H. Spadoti $\mathbb{D}^{2}{ }^{2}$ \\ and S. Arismar Cerqueira Jr. (1) ${ }^{1}$ \\ ${ }^{1}$ Wireless and Optical Convergent Access Laboratory (WOCA), National Institute of Telecommunication (Inatel), \\ Santa Rita do Sapucaí 3754000, Brazil \\ ${ }^{2}$ Department of Institute of Systems Engineering and Information Technology, Federal University of Itajubá (Unifei), \\ Itajubá 37500 903, Brazil \\ Correspondence should be addressed to S. Arismar Cerqueira Jr.; arismar@inatel.br
}

Received 3 May 2019; Revised 4 July 2019; Accepted 23 July 2019; Published 15 September 2019

Guest Editor: Marko Sonkki

Copyright (c) 2019 Andreia A. C. Alves et al. This is an open access article distributed under the Creative Commons Attribution License, which permits unrestricted use, distribution, and reproduction in any medium, provided the original work is properly cited.

\begin{abstract}
This work reports the concept and development of two mechanically frequency-tunable horn filtennas for microwave and millimeter-waves. Our design approach relies on the integration of a horn antenna with a mechanically tunable filter based on dual-post resonators. The proposed filtennas have been manufactured and experimentally characterized, by means of reflection coefficient, radiation pattern, and gain. Measurements demonstrate that both filtennas have a tuning ratio of approximately 1.37 with continuous adjustment. The first prototype operates from 2.56 to $3.50 \mathrm{GHz}$, whereas in the second one the bandwidth is from 17.4 to $24.0 \mathrm{GHz}$. In addition, the higher-frequency filtenna has been implemented in a 5.0 -meter-reach indoor environment, using a 16-QAM signal at $24 \mathrm{GHz}$. The best configuration in terms of performance resulted in a root mean square error vector magnitude $\left(\mathrm{EVM}_{\mathrm{RMS}}\right)$ and antenna radiation efficiency of $3.69 \%$ and $97.0 \%$, respectively.
\end{abstract}

\section{Introduction}

The usage spectrum has been increased significantly in the last decades and trends to accelerate even more in the next years due to the fifth-generation cellular networks (5G). This new generation aims at a 100 -fold increase in traffic capacity $[1,2]$. The motivation to increase the $5 \mathrm{G}$ network bandwidth will probably be the most promising approach to increase the overall capacity. In this direction, the wireless research community needs to exploit efficient and more effective spectrum management techniques [3-7]. Among various approaches, the dynamic spectrum access techniques, including cognitive radio (CR), have been distinguished. Although the use of millimeter-waves (mm-waves) represents a hot topic, low-frequency bands have indeed been considered for $5 \mathrm{G}$ systems [5]. Therefore, the basic structure will be a hybrid network, in which the low- and high-frequency communications coexist $[6,7]$.
In this direction, the demand for new antennas with a capability to work in the newly proposed architectures has increased, and reconfigurable antennas represent a potential candidate to fulfill the $5 \mathrm{G}$ requirements [8-11]. Furthermore, the CR applications require using two different antennas: a broadband antenna for spectrum sensing and a tunable narrowband antenna after selecting the operating channel [12]. Apart from the need of continuously operating through different channels, it becomes necessary to reject those that are not in use. In this way, the filter requirements of the front-end circuits can be greatly reduced.

As an attempt to reduce the hardware complexity, researchers have proposed to move some of the filtering parts to the antenna in order to discharge the filter bank constraints inside the front end. Examples of frequencyreconfigurable antennas with integrated filtering capabilities can be found in [13-16]. A single-port reconfigurable antenna for CR applications was presented in [13]. The 


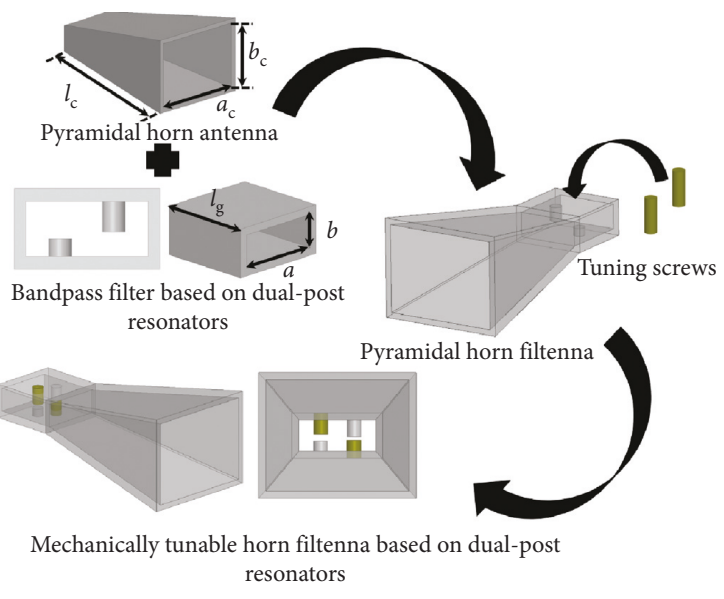

(a)

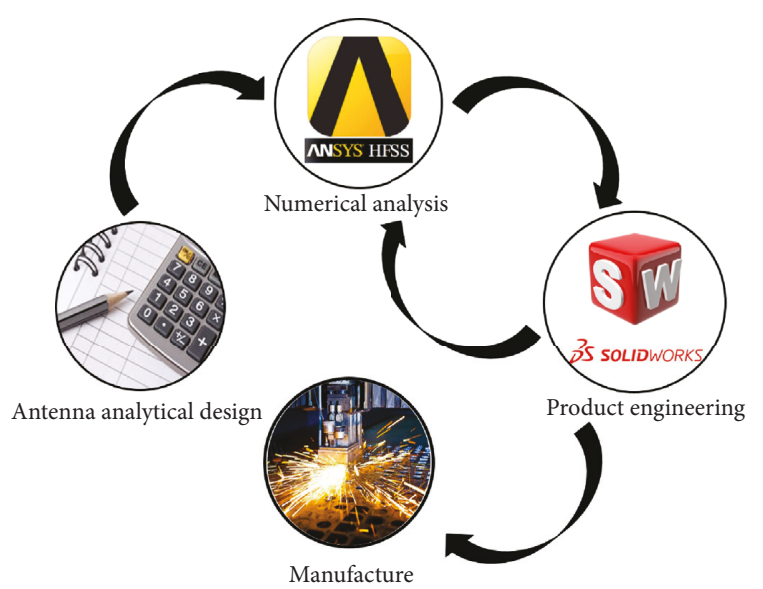

(b)

Figure 1: Horn filtennas design (a) and development methodology (b).

proposed antenna was based on an ultra-wideband (UWB) design and has a reconfigurable bandpass filter integrated into its feed line. Electronic switches were incorporated on the filter to activate/deactivate it and control its bandpass frequency. In [14], a defected microstrip structure (DMS) based on a reconfigurable bandpass filter was integrated with a dual-sided tapered slot antenna. By manipulating the slots in the DMS, the filter could be used for frequency tuning. The authors in [15] presented, for the first time, the filtenna concept. Filtenna or "filtering antenna" is the antenna-filter combination with filtering ability, while preserving the radiation performance. This was achieved by changing the filter total capacitance via an integrated varactor within its structure. We have recently proposed the concept and reported the development of an optically controlled reconfigurable filtenna [16], which was based on the integration of a broadband printed antenna with a bandpass reconfigurable filter and photoconductive switches.

Finally, from the waveguide point of view, there are some publications on filter devices and horn antennas integration, due to its high gain and high efficiency [17-23]. Luo et al. proposed a filtenna structure, in which a horn antenna was covered by a frequency-selective surface (FSS) based on substrate integrated waveguide (SIW) cavities for suppression of out-band interference [17]. In [18], Bilotti et al. reported a self-filtering and low-noise horn antenna for satellite applications. The filtering element was based on metallic omega particles [19]. On the other hand, Barbuto et al. designed a combined bandpass filter and polarization transformer for horn antennas [20]. The solution was based on the design of a linear-to-circular polarization transformer, which consisted of a complementary electrically small resonator etched on a metallic screen. Ma et al. [21] presented a dual circularly polarized horn antenna, by employing a chiral metamaterial composed of two-layered periodic metallic arc structure. The designed antenna provides left-handed circular polarization from 12.4 to $12.5 \mathrm{GHz}$ and right-handed circular polarization from 14.2 to $14.4 \mathrm{GHz}$. Barbuto et al. have used electrically small magnetic resonators to design filtering horn antennas with band-stop characteristics [22]. By properly placing a splitring resonator (SRR) inside a standard horn antenna, the radiating and matching properties of the overall structure are affected by the SRR strong resonance only around its resonant frequency, leading to a band notch filter. Recently, Wang et al. reported a wideband pattern-reconfigurable horn antenna [23]. The antenna consisted of incorporating a power divider, eight reconfigurable band-stop filters, and eight TEM horn antenna elements.

Particularly, we have very recently reported preliminary results of a mechanically tunable horn filtenna [24]. That work is regarding the development of two high-performance reconfigurable and tunable horn filtennas. The first proposed filtenna has been idealized for sub-3.0 GHz bands, which had been recommended by the U.S. Federal Communications Commission for $5 \mathrm{G}$ transmission in urban environments [25]. On the other hand, the second prototype is devoted to mm-wave $5 \mathrm{G}$ systems, which are typically referred to as enhanced mobile broadband applications. The manuscript is structured in five sections. Section 2 is regarding the mechanically tunable horn filtenna design and development methodology. The numerical and experimental results of the two proposed filtennas are presented in Section 3. Section 4 reports an implementation and an experimental performance analysis of the mm-wave horn filtenna. Conclusions and final comments are addressed in Section 5.

\section{Horn Filtenna Design and Development Methodology}

The horn filtennas design and development methodology are presented in Figure 1. Initially, the horn antenna and RF bandpass filter, corresponding to each filtenna, have been analytically calculated as individual structures, with the purpose of satisfying the project requirements. After, they were integrated into a single structure for creating the frequency-reconfigurable filtenna, as illustrated in Figure 1(b). As described in Figure 1(a), the development methodology can be summarized into four phases: the horn antenna and filter analytical design; numerical analysis; 


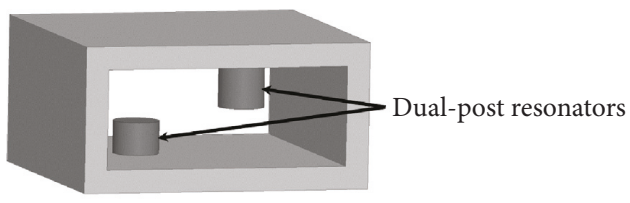

(a)

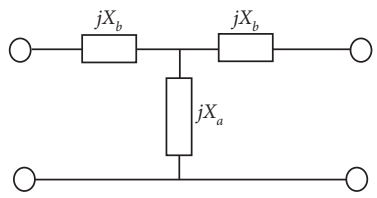

(c)

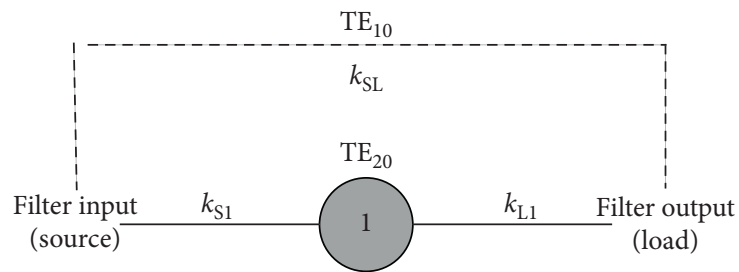

(b)

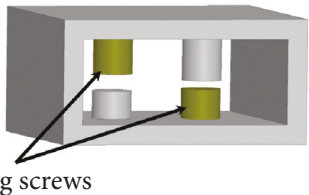

(d)

FIgURE 2: Dual-post resonator filter. (a) The dual-post resonators. (b) The DPR filter singlet schematic. (c) The DPR equivalent circuit. (d) The dual-post resonators and tuning screws variables.

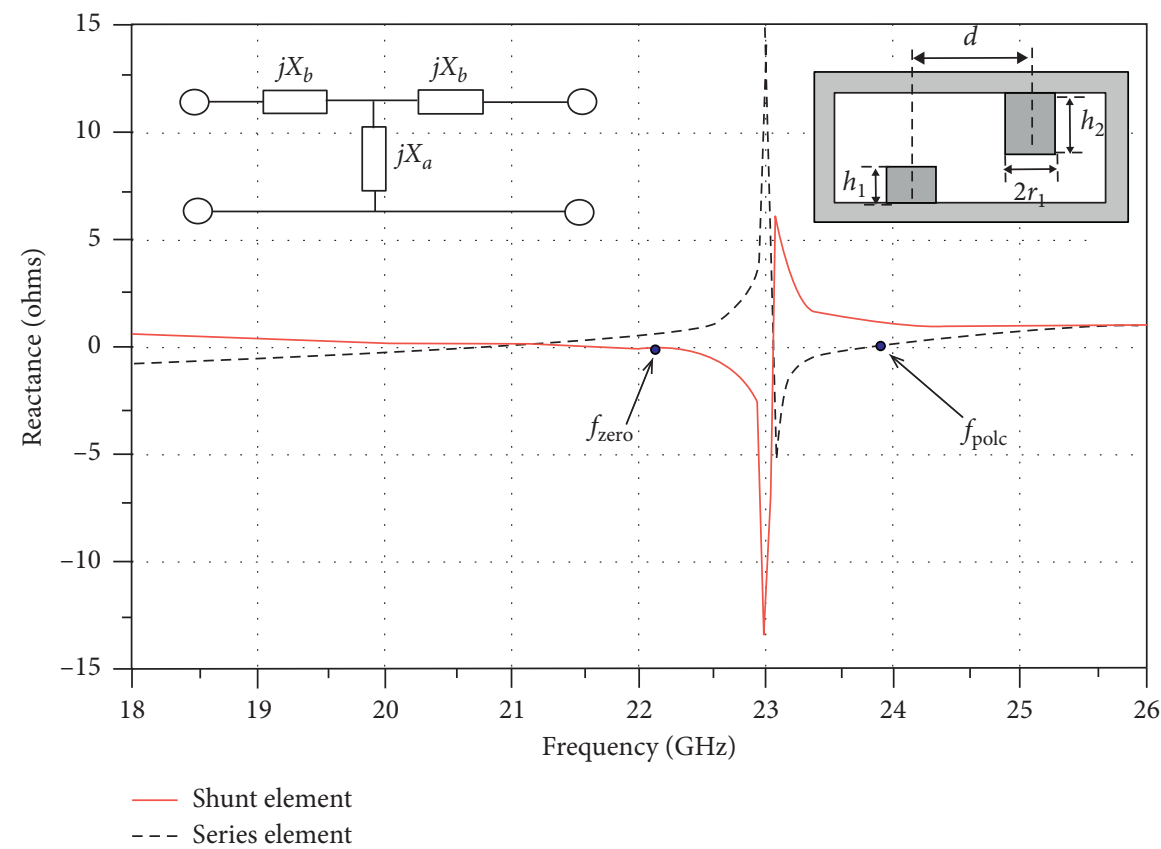

FIgURE 3: The dual-post resonator reactance for $r_{1}=1 \mathrm{~mm}, d=4.67 \mathrm{~mm}, h_{1}=1.4 \mathrm{~mm}$, and $h_{2}=2.4 \mathrm{~mm}$.
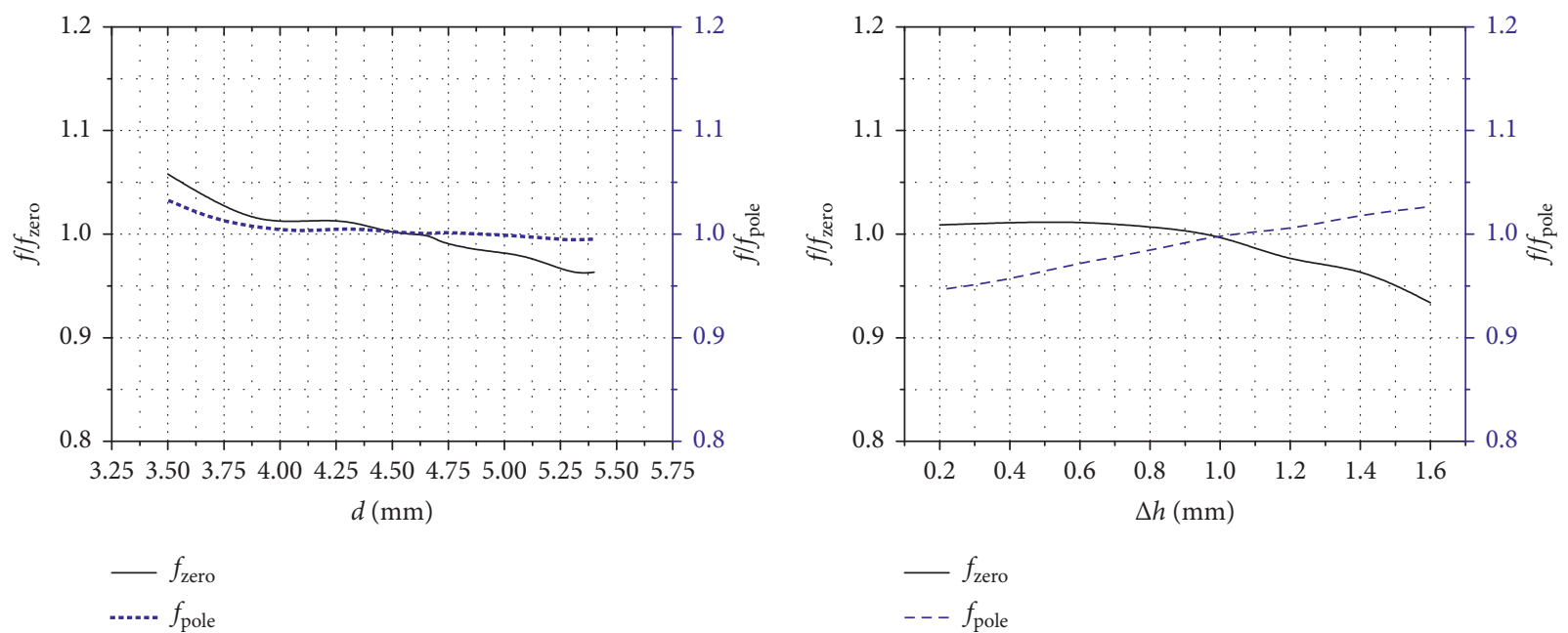

(a)

(b)

Figure 4: Continued. 


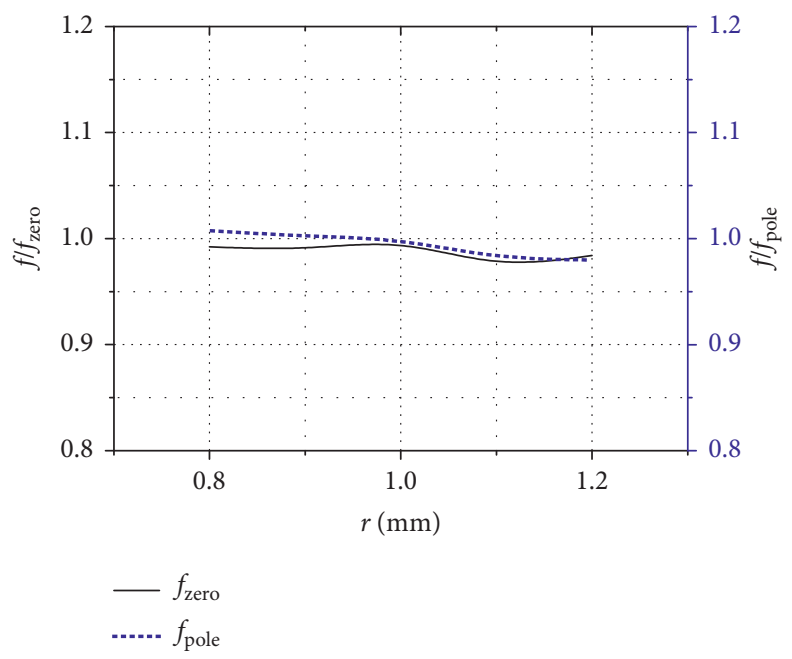

(c)

FIgURE 4: Dual-post resonator design curves example. Transmission zero and pole frequencies as a function of (a) the resonator distance for $r_{1}=1 \mathrm{~mm}, h_{1}=1.4 \mathrm{~mm}$, and $h_{2}=2.4 \mathrm{~mm}$; (b) resonator height difference for $r_{1}=1 \mathrm{~mm}$ and $d=4.67 \mathrm{~mm}$; and (c) resonator radii for $d=4.67 \mathrm{~mm}, h_{1}=1.4 \mathrm{~mm}$, and $h_{2}=2.4 \mathrm{~mm}$.

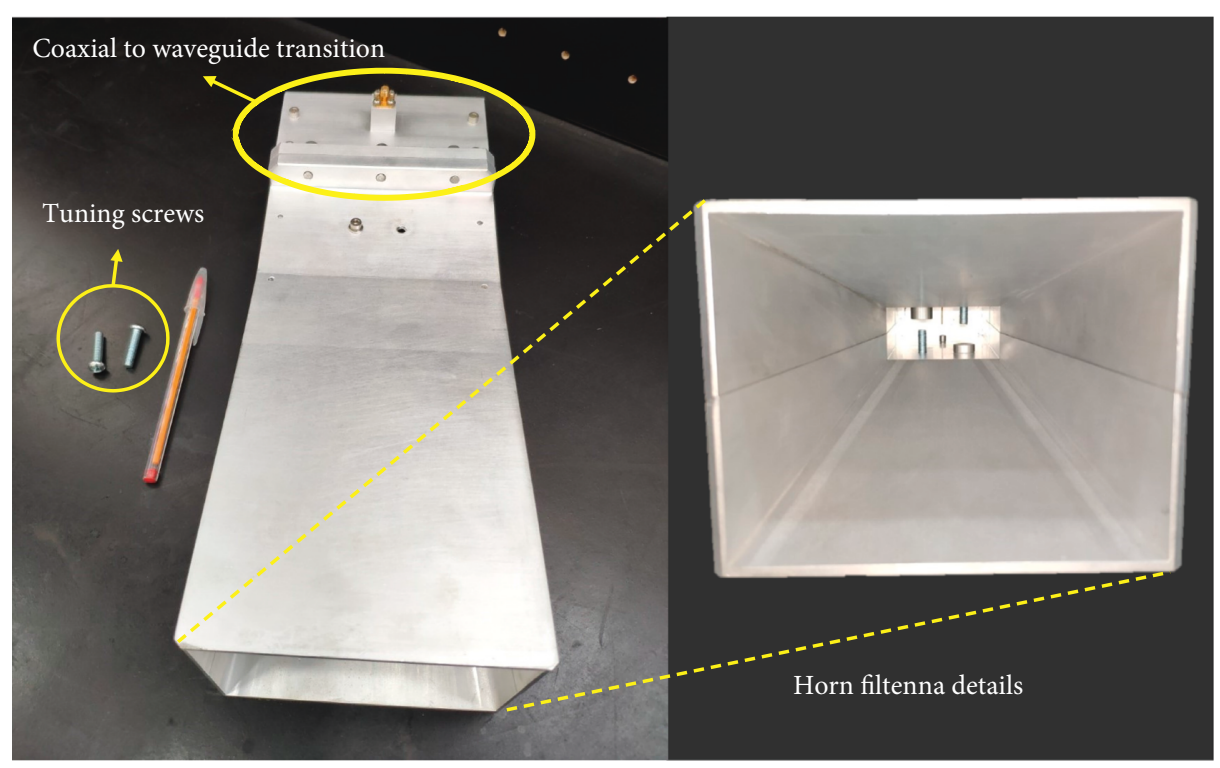

FIGURE 5: Microwave horn filtenna prototype.

product engineering; and manufacture. Numerical sweeps of the filtenna design variables have been performed in ANSYS $\mathrm{HFSS}^{\circledR}$, using the finite element method (FEM), for making its bandwidth reconfigurable without disturbing its radiation pattern. Posteriorly, the antenna model has been modified in product engineering using SolidWorks ${ }^{\circledR}$, giving rise to a mechanical model suitable for prototyping using the milling aluminum process. For electromagnetic validation purposes of the mechanical model, it has exported from SolidWorks ${ }^{\circledR}$, imported in HFSS ${ }^{\circledR}$, and resimulated. Finally, the manufacturing has been realized using the final CAD model, exported from HFSS ${ }^{\circledR}$.

The filtenna radiator is a pyramidal horn antenna with the same half-power beamwidth (HPBW) in the electrical $(E)$ and magnetic $(H)$ field planes. Figure 1(a) displays its design variables: $a$ and $b$ are the waveguide cross-sectional dimension; $l_{\mathrm{g}}$ is the waveguide section length; $a_{\mathrm{c}}$ and $b_{\mathrm{c}}$ are the horn aperture dimensions; and $l_{c}$ is the horn longitudinal length.

The bandpass filter has been placed into the waveguide section between the horn and feeder, without increasing the overall size. The available waveguide section length $l_{\mathrm{g}}$ is less than one guided wavelength at the desired central frequency. Filter topologies such as inductively coupled rectangular waveguide filters, $E$-plane metal insert filters, and evanescent mode waveguide filters have standard structures consisting of several cavities with overall longitudinal length equal or greater than a guided wavelength, which makes them infeasible to this application [26]. On the other side, multimode and dual-post resonator (DPR) filters provide 


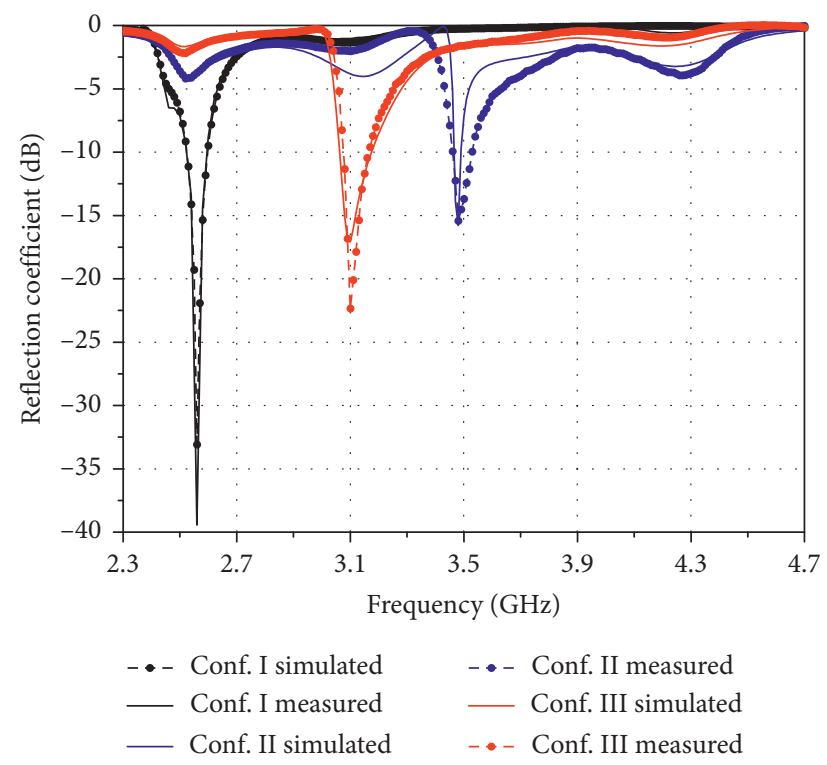

Figure 6: Microwave horn filtenna reflection coefficient. Conf. I $\left(d_{1}=17.70 \mathrm{~mm}\right.$ and $\left.d_{2}=19.96 \mathrm{~mm}\right)$ centered at $2.56 \mathrm{GHz}$; Conf. II $\left(d_{1}=19.0 \mathrm{~mm}\right.$ and $\left.d_{2}=12.3 \mathrm{~mm}\right)$ centered at $3.1 \mathrm{GHz}$; and Conf. III $\left(d_{1}=13.0 \mathrm{~mm}\right.$ and $\left.d_{2}=13.5 \mathrm{~mm}\right)$ centered at $3.5 \mathrm{GHz}$.

compact structures [27-29]. Multimode filters enable multiple resonance frequencies. Its design modifies the waveguide cross-sectional dimensions in order to allow supporting the dominant mode in the vertical and horizontal polarizations for decreasing its longitudinal length [28]. A DPR filter does not change the waveguide main dimensions and is highly selective, easily tunable, and works as inductive obstacles, which are commonly used in conventional waveguide filters. In addition, it is a singlet structure, i.e., with a reflection and a transmission zero at a real frequency [29]. For all these reasons, the DPR approach has been applied to the horn filtenna design.

The DPR filter is a single pole structure composed of two partial-height antipodal metal posts with different lengths and symmetrically located along the waveguide transverse section, as depicted in Figure 2(a). The antipodal position provides a higher difference between the resonant and nonresonant modes than the parallel position, as well as a higher quality factor $(Q)$ [30]. In addition, the different post lengths excite the filter resonant mode without extra coupling sections, reducing the filter overall dimension and complexity [29]. The nonresonant mode defines a resonant frequency away from the filter passband, which might be propagation or an evanescent mode that bypasses the resonant mode [28]. This additional path between the filter input and output ports is used to create a transmission zero in the vicinity of the passband and increase its selectivity. Figure 2(b) presents the filter singlet schematic, in which the $\mathrm{TE}_{20}$ is the DPR filter resonant mode, whereas the nonresonant mode is the $\mathrm{TE}_{10}$ fundamental mode. $\mathrm{TE}_{20}$ generates the filter pole and is coupled to the filter input and output by the coupling coefficients $k_{\mathrm{S} 1}$ and $k_{\mathrm{L} 1}$, respectively. The DPR equivalent circuit is based on inductive obstacles for waveguides [31, 32], as presented in Figure 2(c). The shunt and series elements reactance change from capacitive to inductive, as a function of the DPR height and frequency.
Lastly, $\mathrm{TE}_{10}$ gives rise to a transmission zero located below the resonant mode pole, representing a direct coupling between input and output ports, by a coupling coefficient $k_{\mathrm{SL}}$. The DPR might also be treated as inverter admittance in the filter passband [29]. This approach is commonly used in microwave filters design, with the purpose of allowing a common resonator type for the entire structure [33]. Figure 2(d) shows the dual-post resonator and tuning screws variables, in which $h_{1}$ and $h_{2}$ are the filter resonator lengths; $d$ is the separation between the post resonators; $d_{1}$ and $d_{2}$ are the tuning screw lengths; and $r_{1}$ and $r_{2}$ are the resonator and screw radii, respectively. The metal screws have been inserted into the filter cavity to mechanically tuning the horn filtenna frequency response. The screws have different lengths in order to produce similar loading capacitance, since dual-post resonators have different heights.

The simulated DPR reactance for a WR-42 rectangular waveguide is presented in Figure 3 for $r_{1}=1 \mathrm{~mm}$, $d=4.67 \mathrm{~mm}, h_{1}=1.4 \mathrm{~mm}$, and $h_{2}=2.4 \mathrm{~mm}$. The shunt and series elements reactance had been defined as shown in Figure 2(c) and calculated by $S$-parameters [34]. According to Figure 3, when the shunt element reactance reaches zero, the filter transmission zero frequency $\left(f_{\text {zero }}\right)$ is obtained. Complementarily, when the series element reactance reaches zero, the filter pole frequency $\left(f_{\text {pole }}\right)$ is determined. As a filter design methodology $[24,29,34]$, we have varied the DPR filter design parameters $r_{1}, d$, and $\Delta h=h_{2}-h_{1}$ for illustrating their impact on the transmission zero and pole frequencies. The DPR design curves are reported in Figure 4, including the normalized transmission zero and pole frequencies. First, the DPR transmission zero frequency is inversely proportional to resonators separation distance $d$, as reported in Figure 4(a). The pole frequency is practically insensitive to the resonator separation distance; only for small values of $d$, the pole frequency slightly increases. Figure 4(b) presents the DPR frequency response as a function of the resonator 


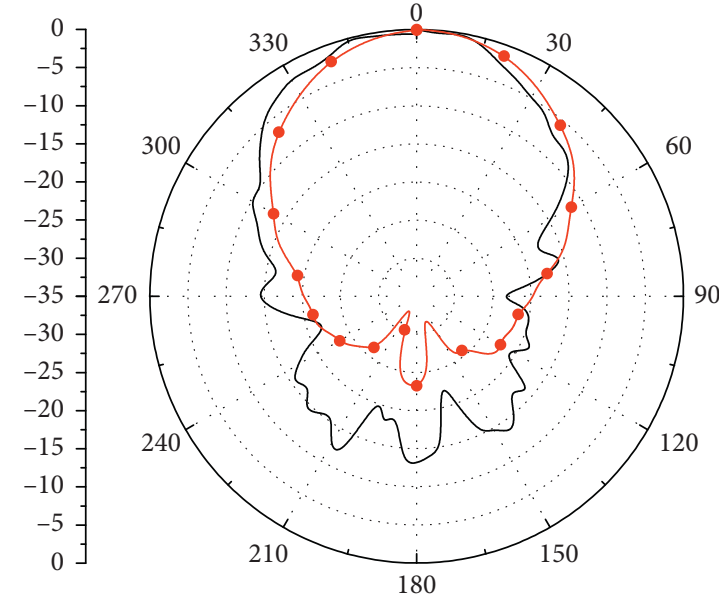

- Measured

$\rightarrow$ Simulated

(a)

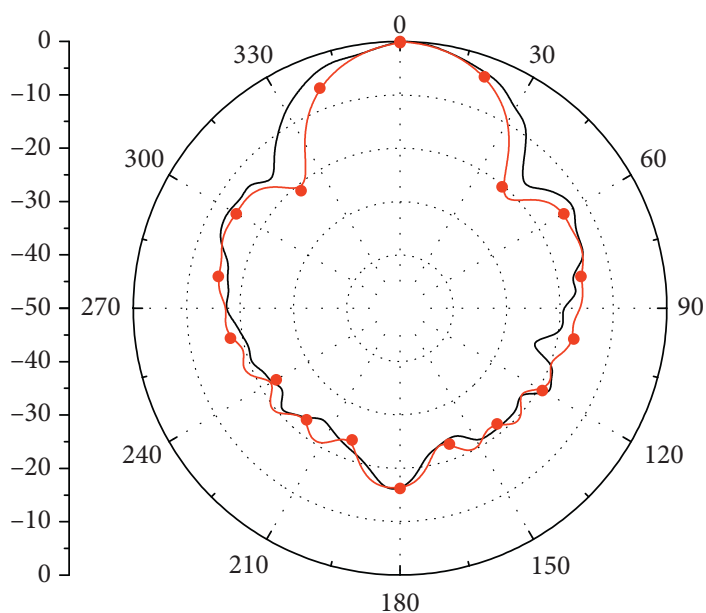

$\longrightarrow$ Measured

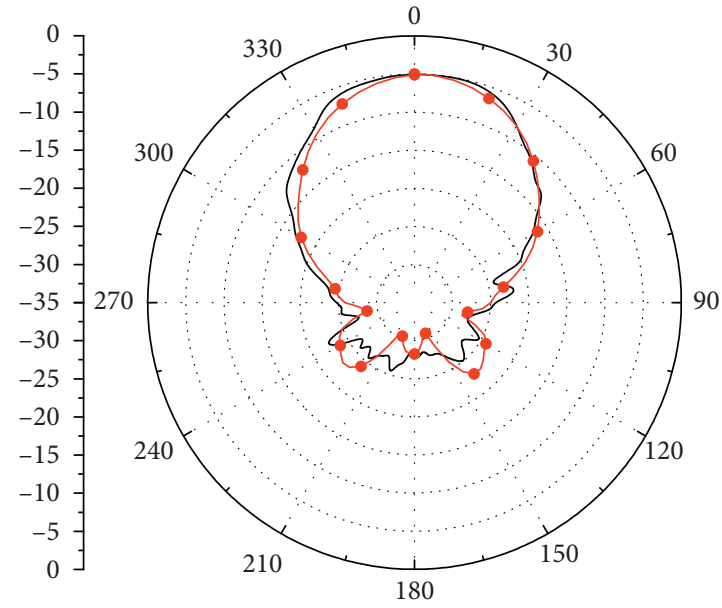

- Measured

$\longrightarrow$ Simulated

(b)

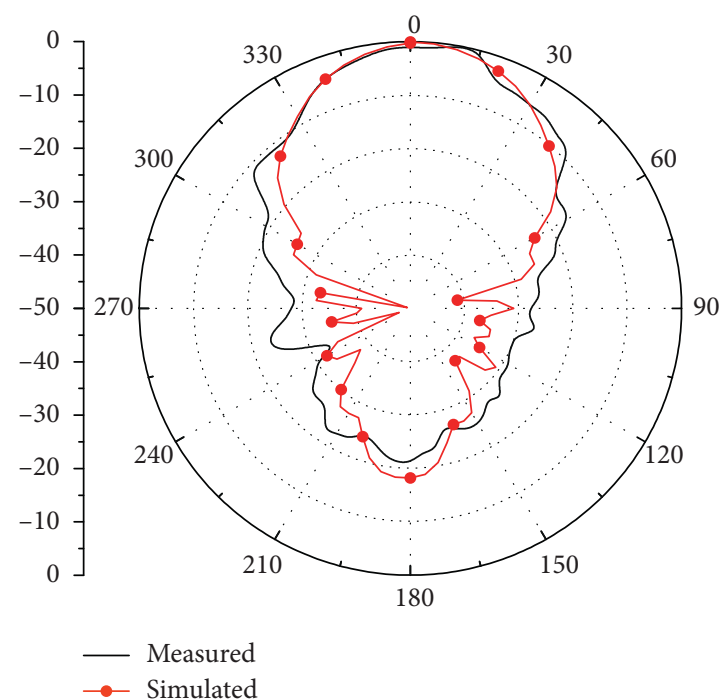

(d)

Figure 7: Microwave horn filtenna radiation pattern. (a) E-plane at 2.56 GHz. (b) H-plane at 2.56 GHz. (c) E-plane at $3.50 \mathrm{GHz}$. (d) H-plane at $3.50 \mathrm{GHz}$.

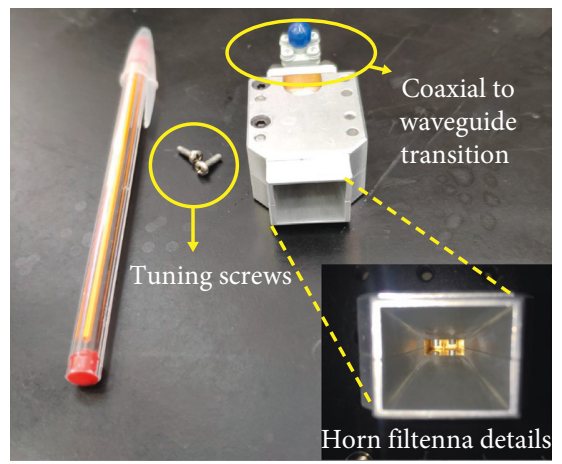

Figure 8: Millimeter-wave horn filtenna prototype. 


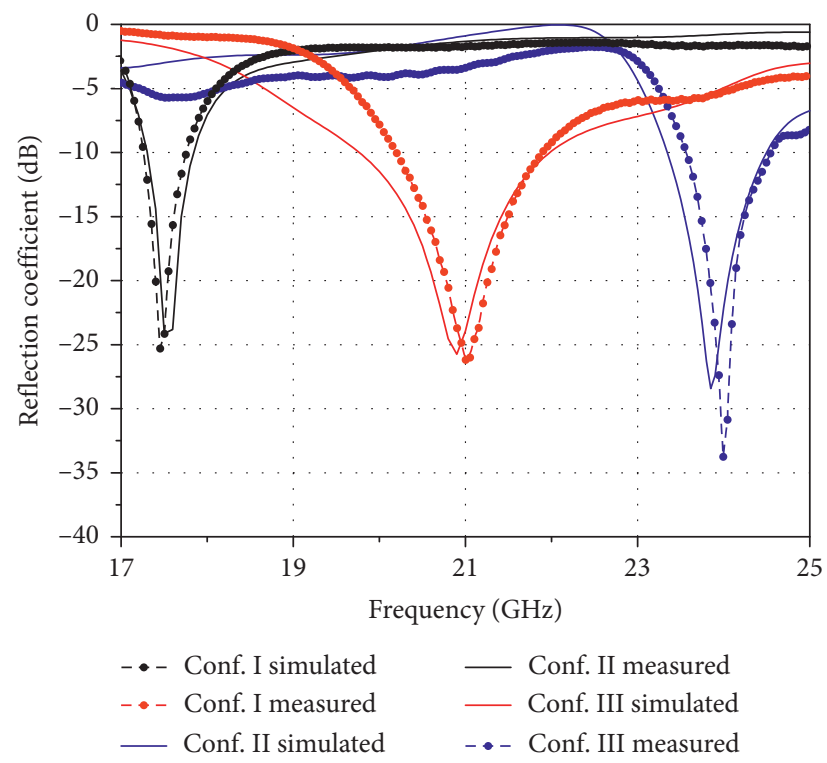

Figure 9: Millimeter-wave horn filtenna reflection coefficient. Conf. I $\left(d_{1}=2.55 \mathrm{~mm}\right.$ and $\left.d_{2}=0 \mathrm{~mm}\right)$ centered at $17.4 \mathrm{GHz}$; Conf. II $\left(d_{1}=0.85 \mathrm{~mm}\right.$ and $\left.d_{2}=1.8 \mathrm{~mm}\right)$ centered at $21 \mathrm{GHz}$; Conf. III $\left(d_{1}=0.5 \mathrm{~mm}\right.$ and $\left.d_{2}=1 \mathrm{~mm}\right)$ centered at $24 \mathrm{GHz}$.

height difference. This parameter is directly proportional to the pole frequency and controls the DPR filter passband. The transmission zero frequency is stable for small values of $\Delta h$ and starts to decrease after the $1 \mathrm{~mm}$ threshold. Finally, the results for resonators radii variation are presented in Figure 4(c). The transmission zero and pole frequencies have small dependence on the resonator radii, for this reason cannot be used as a tuning parameter. In short, $d$ is used to control the transmission zero frequency, whereas the pole frequency is controlled by $\Delta h$. The resonator radii might be defined according to the manufacturing process constraints. As a conclusion, DPR filters can be efficiently designed by applying the presented circuital model and design curves, since no closed formulas have been obtained for its structure yet.

\section{Horn Filtennas Results}

This section reports the numerical and experimental results of the two proposed filtennas, namely, microwave horn filtenna and millimeter-wave horn filtenna.

3.1. Microwave Horn Filtenna. For the microwave horn filtenna, a noncommercial waveguide $(a=66 \mathrm{~mm}$ and $b=30 \mathrm{~mm}$ ) has been designed in order to cover the frequency range from 2.56 to $3.50 \mathrm{GHz}$ with single mode operation $\left(\mathrm{TE}_{10}\right)$. The horn filtenna final dimensions were $a_{\mathrm{c}}=127.65 \mathrm{~mm}, b_{\mathrm{c}}=98.3 \mathrm{~mm}$, and $l_{\mathrm{c}}=212.73 \mathrm{~mm}$. The waveguide section between the feeder and radiator with length equal to $l_{\mathrm{g}}=80 \mathrm{~mm}$ has been used to design the DPR filter. The resonators were positioned in the waveguide center, separated by a distance $d=27 \mathrm{~mm}$ and with a radius equal to $7.0 \mathrm{~mm}$. By considering the desired range from 2.56 to $3.50 \mathrm{GHz}$, the resonators lengths $h_{1}=5.1 \mathrm{~mm}$ and $h_{2}=9.1 \mathrm{~mm}$ were obtained by numerical sweep in ANSYS
HFSS. A few interactions between HFSS and SolidWorks have been done to obtain a suitable and feasible filtenna mechanical model. Figure 5 reports the resultant prototype made in aluminum.

A waveguide to coaxial transition has also been developed to facilitate its connection to RF components and pieces of equipment. The filtenna characterization starts from reflections $\left(S_{11}\right)$ measurements, using the Keysight PNA Network Analyzer N5224A for different screw depths. The filtenna operating frequency could be continuously tuned from 2.56 to $3.50 \mathrm{GHz}$ by appropriately tightening the tuning screws. Figure 6 presents the reflection coefficient response for the initial, central, and final frequencies for both simulations and measurements. The filtenna operating modes have been defined as Conf. I $\left(d_{1}=17.70 \mathrm{~mm}\right.$ and $\left.d_{2}=19.96 \mathrm{~mm}\right)$; Conf. II $\left(d_{1}=19.0 \mathrm{~mm}\right.$ and $\left.d_{2}=12.3 \mathrm{~mm}\right)$; and Conf. III $\left(d_{1}=13.0 \mathrm{~mm}\right.$ and $\left.d_{2}=13.5 \mathrm{~mm}\right)$. The filtenna bandwidth can be managed by manipulating $d_{1}$ and $d_{2}$, since the loading capacitance is proportional to the screws' depths. An excellent agreement is observed between the measured and simulated results for the three operating modes. The measured filtenna central frequency and fractional bandwidth (FBW) were $2.56 \mathrm{GHz}$ and $2.7 \%$ for Conf. I; $3.10 \mathrm{GHz}$ and $2.8 \%$ for Conf. II; and $3.50 \mathrm{GHz}$ and $2 \%$ for Conf. III. The microwave horn filtenna tuning ratio was approximately 1.36 , which is higher than most of the tunable filtenna reported in the literature [13-15] that are typically based on microstrip antennas. Additionally, the main advantage of our approach is the remarkable possibilities of continuously tuning the bandwidth due to use of dual-post resonator structure.

The filtenna radiation pattern and gain measurements were performed using a standard log-periodic antenna as a reference antenna, positioned $7 \mathrm{~m}$ away. Both antennas were mounted on masts at $1.8 \mathrm{~m}$. Radiation pattern measurements has been carried out at 2.56 


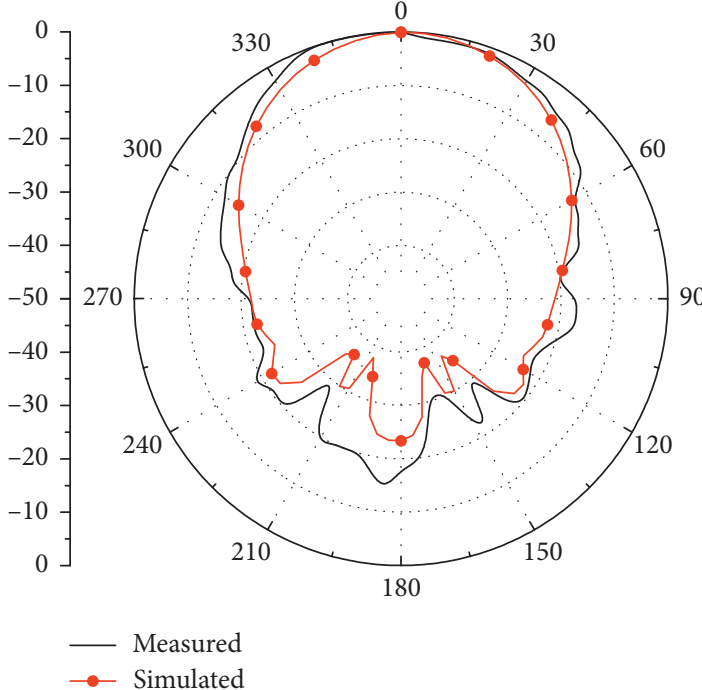

(a)

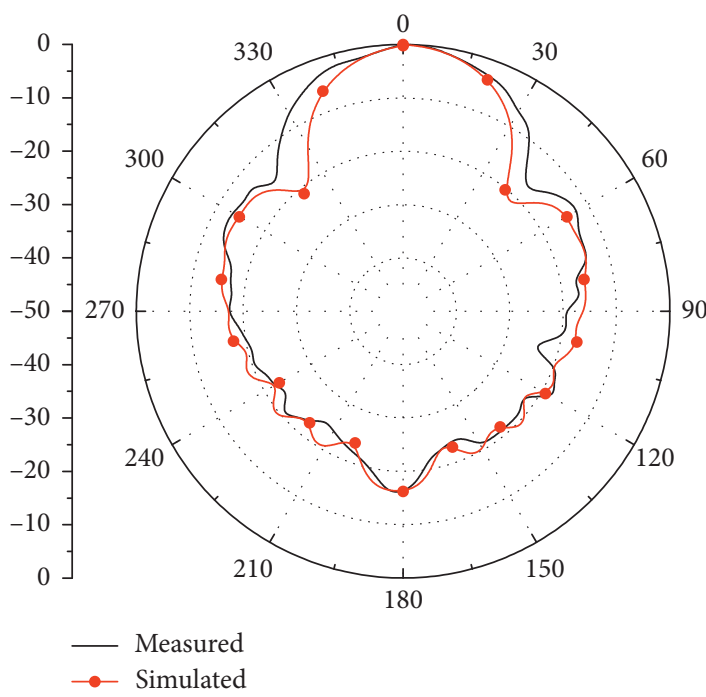

(c)

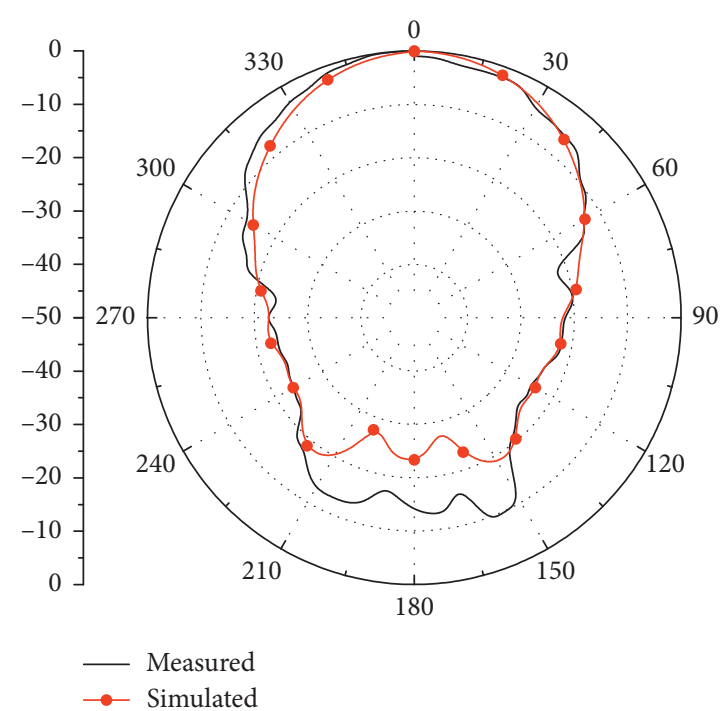

(b)

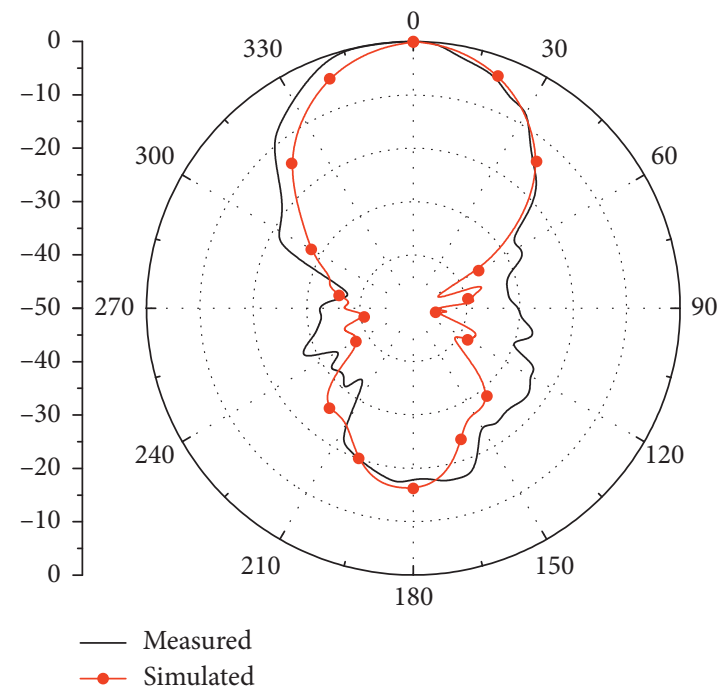

(d)

FIGURE 10: Millimeter-wave horn antenna radiation pattern. (a) E-plane at $17.5 \mathrm{GHz}$. (b) $H$-plane at $17.5 \mathrm{GHz}$. (c) E-plane at $24 \mathrm{GHz}$. (d) $H$-plane at $24 \mathrm{GHz}$.

and $3.50 \mathrm{GHz}$ for $E$-plane and $H$-plane, as summarized in Figure 7. A discrepancy at $2.56 \mathrm{GHz}$ in the front-back region for $E$-plane is observed in Figure 7(a). Regarding the main lobe, the measured and simulated results have consistently been shown for all frequencies and planes. The measured peak gain was $8 \mathrm{dBi}$ at $2.56 \mathrm{GHz}$ and $10 \mathrm{dBi}$ at $3.50 \mathrm{GHz}$.

3.2. Millimeter-Wave Horn Filtenna. A standard waveguide WR-42 $(10.67 \mathrm{~mm} \times 4.3 \mathrm{~mm})$ has been used for the $\mathrm{mm}$ wave horn filtenna and its final dimensions were $a_{\mathrm{c}}=19.88 \mathrm{~mm}, b_{\mathrm{c}}=15.46 \mathrm{~mm}$, and $l_{\mathrm{c}}=33.13 \mathrm{~mm}$. Following the same design procedure adopted for the microwave horn filtenna, the waveguide section between the feeder and radiator $\left(l_{\mathrm{g}}=12 \mathrm{~mm}\right)$ has been used for allocating the DPR filter. The $2 \mathrm{~mm}$ diameter resonators were positioned in the waveguide center with a separation distance of $4.67 \mathrm{~mm}$. The resonator heights are $h_{1}=1.4 \mathrm{~mm}$ and $h_{2}=2.4 \mathrm{~mm}$ from 17.4 to $24.0 \mathrm{GHz}$. Figure 8 presents the mm-wave filtenna prototype, manufactured by milling process in aluminum.

The filtenna reflection coefficient has been measured using a Keysight PNA Network Analyzer N5224A and a commercial waveguide to coaxial transition. The measured results are presented in Figure 9 for the initial, central, and final frequency, from 17.4 to $24.0 \mathrm{GHz}$. Once again, the filtenna bandwidth could be continuously tuned over a wide frequency range. The measured and simulated results presented in Figure 9 corroborate with the proposed horn filtenna design procedure. The filtenna measured operating modes according to screws positions are Conf. I $\left(d_{1}=2.55 \mathrm{~mm}\right.$ and $\left.d_{2}=0 \mathrm{~mm}\right)$ centered at $17.4 \mathrm{GHz}$ with $2.8 \%$ FBW; Conf. II $\left(d_{1}=0.85 \mathrm{~mm}\right.$ and 


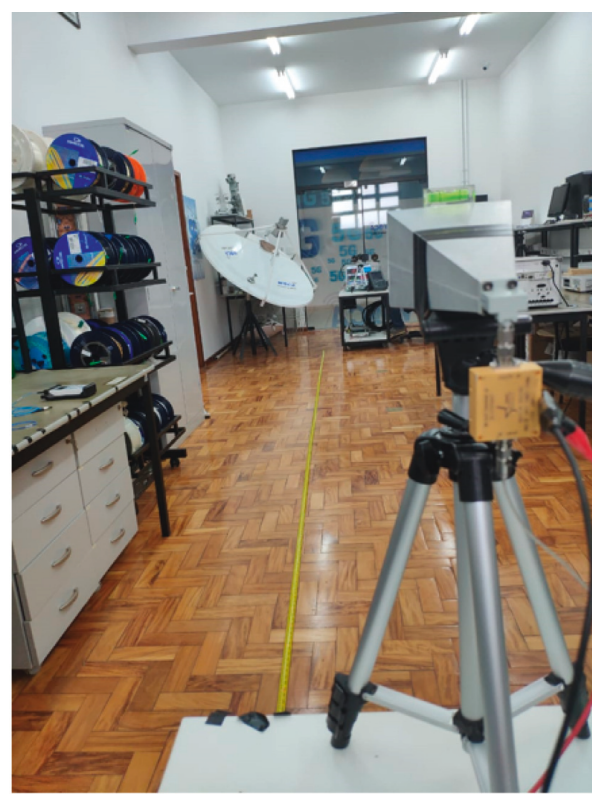

(a)

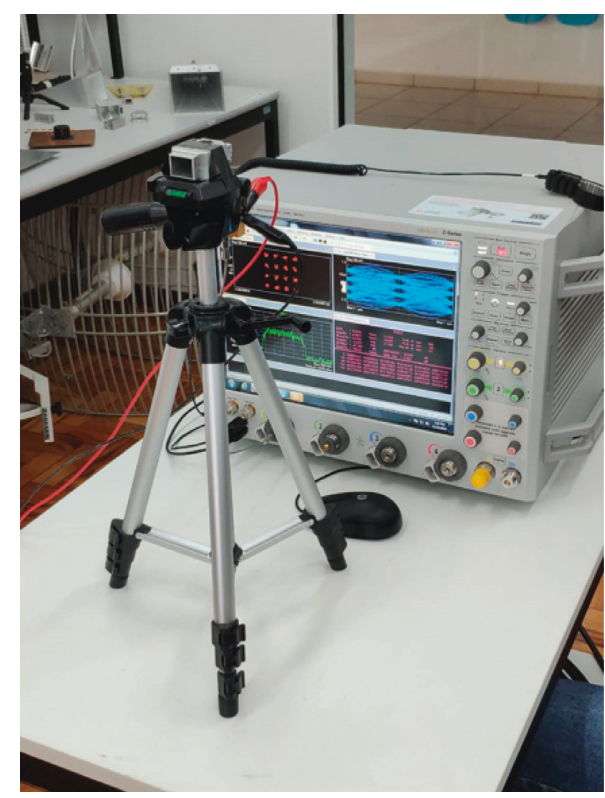

(b)

FIGURE 11: Implementation of the mm-wave tunable horn filtenna at $24.7 \mathrm{GHz}$. (a) Transmission side and (b) reception side.

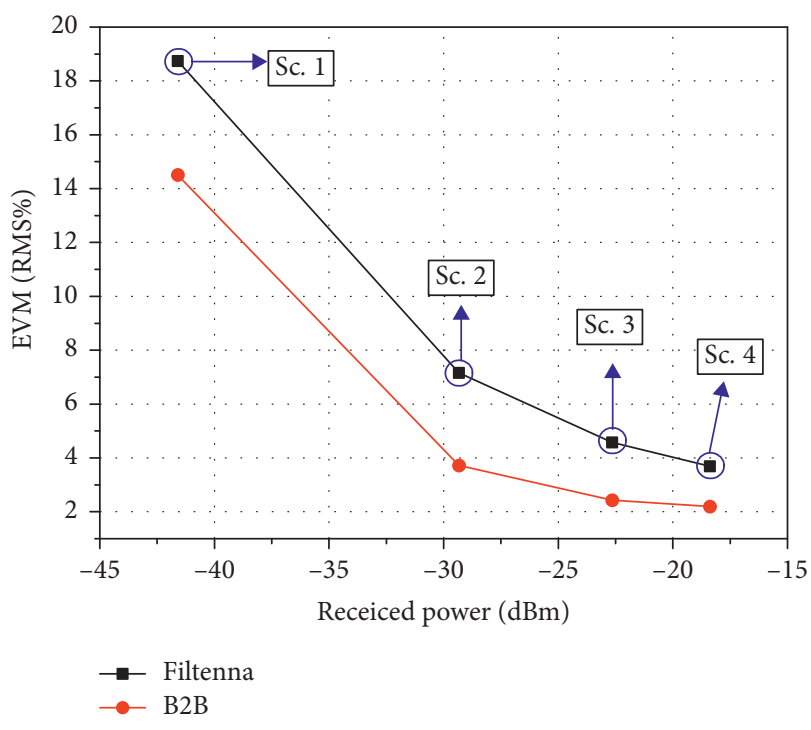

FIGURE 12: EVM as a function of the received power for four different scenarios.

$d_{2}=1.8 \mathrm{~mm}$ ) centered at $21 \mathrm{GHz}$ with $7.9 \% \mathrm{FBW}$; and Conf. III $\left(d_{1}=0.5 \mathrm{~mm}\right.$ and $\left.d_{2}=1 \mathrm{~mm}\right)$ centered at $24 \mathrm{GHz}$ with $4.11 \%$ FBW. The millimeter-wave horn filtenna tuning ratio is approximately 1.37 with FBW from 2.8 to $7.9 \%$.

Radiation pattern measurements have been carried out at 17.5 and $24 \mathrm{GHz}$ for the $E$-plane and $H$-plane, as summarized in Figure 10. A good qualitative agreement is observed for all cases, mainly for the half-power beamwidth. The main difference is related to the back lobe for the $H$-plane at $17.5 \mathrm{GHz}$. Its measured peak gain was $8.5 \mathrm{dBi}$ and $12.3 \mathrm{dBi}$ at 17.5 and $24.0 \mathrm{GHz}$, respectively.

\section{Implementation of the Millimeter-Wave Tunable Horn Filtenna}

Our main objective was demonstrating its applicability in radio cognitive, in which operating bandwidth can be dynamically allocated as a function of the opportunistic scenario of primary/secondary users. Figure 11 displays photographs of the indoor environments used for the implementation. At the transmission side, a vector signal generator (VSG) provides a 16-QAM of $800 \mathrm{Mb} / \mathrm{s}$ signal at 24.7 GHz. The RF power transmission was $1 \mathrm{dBm}$, and an electrical amplifier (EA) with $23 \mathrm{~dB}$ gain was applied in order to increase the effectively radiated power by the filtenna. The transmission antenna was a $20 \mathrm{dBi}$ gain horn antenna. The free-space loss, calculated by the Friis equation, was approximately $55.8 \mathrm{~dB}$ at $24.7 \mathrm{GHz}$ for 5 meters. The received side was composed by the $\mathrm{mm}$-wave filtenna followed by a low-noise amplifier and a vector signal analyzer (VSA).

Figure 12 reports the experimental results of the root mean square error vector magnitude $\left(E_{\mathrm{RMS}}\right)$ as a function of the received power. In accordance with 3GPP

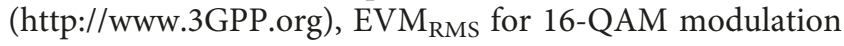
should not exceed $12.5 \%$ [35]. For comparison purposes, the red curve depicts a back-to-back (B2B) condition by directly connecting VSG to VSA. In other words, there was no wireless transmission for the B2B scenario. The black curve with squares represents the wireless transmission for four different scenarios (Sc.) based on the screw depth position. Sc. 1 was the worst case, for which the filtenna does not provide a suitable impedance matching at the chosen frequency with these screw depths configuration; thus, the constellation has been shown poor, giving rise to $\mathrm{EVM}_{\mathrm{RMS}}$ of $18.47 \%$. As soon as the screw depths were modified, the system performance has been significantly improved, 


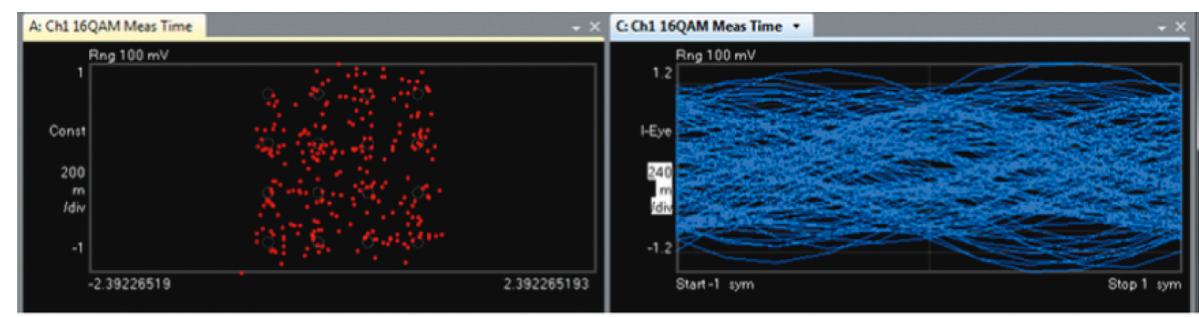

(a)

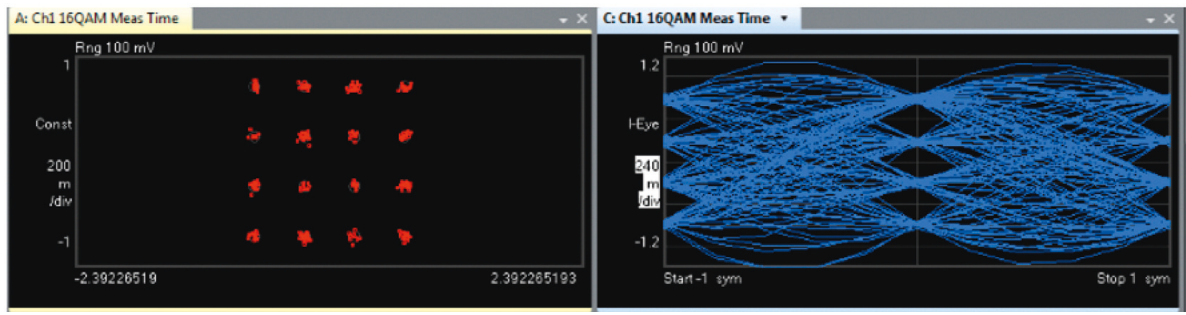

(b)

FIGURE 13: Experimental performance investigation at $24.7 \mathrm{GHz}$ with $800 \mathrm{Mbit} / \mathrm{s}$ throughput. (a) Scenario 1 and (b) Scenario 4.

TABLE 1: Experimental characterization of the proposed filtenna for four configurations.

\begin{tabular}{|c|c|c|c|c|c|c|}
\hline Scenario & Screw depth $(\mathrm{mm})$ & $S_{11}(\mathrm{~dB})$ & Radiation efficiency (\%) & Received power $(\mathrm{dBm})$ & EVM (RMS\%) & SNR $(\mathrm{dB})$ \\
\hline Sc. 1 & $d_{1}=1.2 d_{2}=1.8$ & -1 & 18.25 & -41.64 & 18.47 & 11.54 \\
\hline Sc. 2 & $d_{1}=0.8 \quad d_{2}=1.4$ & -7 & 73.86 & -29.32 & 7.155 & 24.17 \\
\hline Sc. 3 & $d_{1}=0.6 d_{2}=1.2$ & -15 & 87.16 & -22.64 & 4.58 & 20.31 \\
\hline Sc. 4 & $d_{1}=0.5 d_{2}=1$ & -20 & 97.8 & -18.46 & 3.69 & 11.54 \\
\hline
\end{tabular}

resulting $\mathrm{EVM}_{\mathrm{RMS}}$ and power received of $3.69 \%$ and $-18.46 \mathrm{dBm}$, respectively. Additionally, Figure 13(a) and Figure 13(b) depict the experimental performance results at $800 \mathrm{Mbit} / \mathrm{s} \mathrm{RF}$ signal in terms of the constellation and eye diagram for Sc. 1 and Sc. 4, respectively.

As explained and demonstrated in the previous section, the filtenna bandwidth can be efficiently managed by optimizing the screws depths of the DPR filter. Its reflection coefficient at $24.7 \mathrm{GHz}$ varies from -1 to $-20 \mathrm{~dB}$, deepening on the screw depths. Accordingly, the filtenna radiation efficiency alters from 18 to $97 \%$. Table 1 summarizes the experimental results scenarios. These experimental results demonstrate the applicability of the proposed tunable horn filtenna for radio cognitive in the mm-wave.

\section{Conclusions}

This paper reported the development of two high-performance continuously frequency-tunable horn filtennas for microwave and mm-waves. Both filtennas are based on the integration of a broadband horn antenna with a dual-post resonator filter for enabling mechanical reconfiguration of their bandwidth. Numerical simulations and experimental results have been shown in excellent agreement, and a tuning ratio of 1.36 and 1.37 for the lower-frequency (from 2.56 to $3.5 \mathrm{GHz}$ ) and higher-frequency (from 17.4 to $24 \mathrm{GHz}$ ) filtennas has been reported, respectively. Additionally, the mm-wave horn filtenna has been implemented in a highthroughput indoor wireless system at $800 \mathrm{Mbps}$ with line of sight. The experimental analysis as a function of diverse performance metrics (constellation, eye diagram, EVM, and SNR) has successfully demonstrated the applicability of the proposed filtenna in cognitive radio applications, for instance, mm-wave $5 \mathrm{G}$ systems. It has been obtained a measured $\mathrm{EVM}_{\mathrm{RMS}}$ as low as $3.69 \%$, which is far below the 3 GPP requirement of $12.5 \%$ for 16 -QAM. Future works regard the implementation of either microwave and $\mathrm{mm}$ wave filtenna in a real $5 \mathrm{G}$ network based on the use of the Brazilian 5G transceiver, which has been previously developed by our research group [36].

\section{Data Availability}

No data were used to support this study.

\section{Conflicts of Interest}

The authors declare that are no conflicts of interest regarding the publication of this paper.

\section{Acknowledgments}

This work was partially supported by RNP, with resources from MCTIC, Grant no. 01250.075413/2018-04, under the Radiocommunication Reference Center (Centro de Referência em Radiocomunicações-CRR) project of the National Institute of Telecommunications (Instituto Nacional de Telecomunicações-Inatel), 
Brazil. The authors also thank the financial support from CNPq, CAPES, FINEP, and FAPEMIG.

\section{References}

[1] G. Liu and D. Jiang, "5G: vision and requirements for mobile communication system towards year 2020," Chinese Journal of Engineering, vol. 2016, Article ID 5974586, 8 pages, 2016.

[2] G. Kalfas, C. Vagionas, A. Antonopoulos et al., "Next generation fiber-wireless fronthaul for $5 \mathrm{G} \mathrm{mm}$ wave networks," IEEE Communications Magazine, vol. 57, no. 3, pp. 138-144, 2019.

[3] P. Masek, E. Mokrov, K. Zeman et al., "A practical perspective on 5G-ready highly dynamic spectrum management with LSA," Wireless Communications and Mobile Computing, vol. 2018, Article ID 2103868, 10 pages, 2018.

[4] A. Roy, S. Sengupta, K.-K. Wong, V. Raychoudhury, K. Govindan, and S. Singh, " $5 \mathrm{G}$ wireless with cognitive radio and massive IoT", "IETE Technical Review, vol. 34, no. 1, pp. 1-3, 2017.

[5] K. Xiao, W. Li, M. Kadoch, and C. Li, "On the secrecy capacity of $5 \mathrm{Gmm}$ wave small cell networks," IEEE Wireless Communications, vol. 25, no. 4, pp. 47-51, 2018.

[6] M. S. Omar, M. A. Anjum, S. A. Hassan, H. Pervaiz, and Q. Niv, "Performance analysis of hybrid 5G cellular networks exploiting $\mathrm{mm}$ wave capabilities in suburban areas," in Proceedings of the 2016 IEEE International Conference on Communications (ICC), pp. 1-6, Kuala Lumpur, Malaysia, May 2016.

[7] G. Ghatak, A. De Domenico, and M. Coupechoux, "Coverage analysis and load balancing in HetNets with millimeter wave multi-RAT small cells," IEEE Transactions on Wireless Communications, vol. 17, no. 5, pp. 3154-3169, 2018.

[8] J. T. Bernhard, "Reconfigurable antennas," in Encyclopedia of $R F$ and Microwave Engineering, K. Chang, Ed., Wiley, New York, NY, USA, 2005.

[9] I. F. da Costa, D. H. Spadoti, A. C. Sodré Jr. et al., "Optically controlled reconfigurable antenna for $5 \mathrm{G}$ future broadband cellular communication networks," Journal of Microwaves, Optoelectronics and Electromagnetic Applications, vol. 16, no. 1, pp. 208-217, 2017.

[10] A. Boukarkar, X. Q. Lin, Y. Jiang, Y. J. Chen, L. Y. Nie, and P. Mei, "Compact mechanically frequency and pattern reconfigurable patch antenna," IET Microwaves, Antennas \& Propagation, vol. 12, no. 11, pp. 1864-1869, 2018.

[11] L. Safatly, M. Bkassiny, M. Al-Husseini, and A. El-Hajj, "Cognitive radio transceivers: $\mathrm{RF}$, spectrum sensing, and learning algorithms review," International Journal of Antennas and Propagation, vol. 2014, Article ID 548473, 21 pages, 2014.

[12] J. Kelly, E. Ebrahimi, P. S. Hall, P. Gardner, and F. Ghanem, "Combined wideband and narrowband antennas for cognitive radio applications," in Proceedings of the lET seminar on Cognitive Radio and Software Defined Radios: Technologies and Techniques, London, UK, September 2008.

[13] M. Zamudio, Y. Tawk, J. Costantine, J. Kim, and C. G. Christodoulou, "Integrated cognitive radio antenna using reconfigurable band pass filters," in Proceedings of the 5th European Conference on Antennas and Propagation (EUCAP), pp. 2108-2112, Rome, Italy, April 2011.

[14] M. Al-Husseini, A. Ramadan, M. E. Zamudio, C. G. Christodoulou, A. El-Hajj, and K. Y. Kabalan, “A UWB antenna combined with a reconfigurable bandpass filter for cognitive radio applications," in Proceedings of the 2011 IEEE-APS Topical Conference on Antennas and Propagation in Wireless Communications, pp. 902-904, Torino, Italy, September 2011.

[15] Y. Tawk, J. Costantine, and C. G. Christodoulou, "A varactorbased reconfigurable filtenna," IEEE Antennas and Wireless Propagation Letters, vol. 11, pp. 716-719, 2012.

[16] L. G. Silva, A. A. C. Alves, and A. C. Sodré Jr., "Optically controlled reconfigurable filtenna," International Journal of Antennas and Propagation, vol. 2016, Article ID 7161070, 9 pages, 2016.

[17] G. Q. Luo, W. Hong, H. J. Tang et al., "Filtenna consisting of horn antenna and substrate integrated waveguide cavity FSS," IEEE Transactions on Antennas and Propagation, vol. 55, no. 1, pp. 92-98, 2007.

[18] F. Bilotti, L. Di Palma, D. Ramaccia, and A. Toscano, "Selffiltering low-noise horn antenna for satellite applications," IEEE Antennas and Wireless Propagation Letters, vol. 11, pp. 354-357, 2012.

[19] D. Ramaccia, L. Di Palma, D. Ates, E. Ozbay, A. Toscano, and F. Bilotti, "Analytical model of connected Bi-omega: robust particle for the selective power transmission through subwavelength apertures," IEEE Transactions on Antennas and Propagation, vol. 62, no. 4, pp. 2093-2101, 2014.

[20] M. Barbuto, F. Trotta, F. Bilotti, and A. Toscano, "A combined bandpass filter and polarization transformer for horn antennas," IEEE Antennas and Wireless Propagation Letters, vol. 12, pp. 1065-1068, 2013.

[21] X. Ma, C. Huang, W. Pan, B. Zhao, J. Cui, and X. Luo, "A dual circularly polarized horn antenna in Ku-band based on chiral metamaterial," IEEE Transactions on Antennas and Propagation, vol. 62, no. 4, pp. 2307-2311, 2014.

[22] M. Barbuto, F. Trotta, F. Bilotti, and A. Toscano, "Varying the operation bandwidth of metamaterial-inspired filtering modules for horn antennas," Progress in Electromagnetics Research C, vol. 58, pp. 61-68, 2015.

[23] Z. Wang, P. S. Hall, J. R. Kelly, and P. Gardner, "Wideband frequency-domain and space-domain pattern reconfigurable circular antenna array," IEEE Transactions on Antennas and Propagation, vol. 65, no. 10, pp. 5179-5189, 2017.

[24] A. A. C. Alves, L. G. da Silva, E. C. V. Boas, D. H. Spadoti, and A. C. Sodré Jr., "Mechanically tunable horn filtenna for mmwaves," in Proceedings of EUCAP 2019 European Conference on Antennas and Propagation, Krakow, Poland, March-April 2019.

[25] WRC-15 documents and proposals, 2015, https://www.itu.int/en/ ITU-R/conferences/wrc/2015/Pages/docsandprops.aspx.

[26] V. Boria and B. Gimeno, "Waveguide filters for satellites," IEEE Microwave Magazine, vol. 8, no. 5, pp. 60-70, 2007.

[27] S. Amari and U. Rosenberg, "Characteristics of cross (bypass) coupling through higher/lower order modes and their applications in elliptic filter design," IEEE Transactions on Microwave Theory and Techniques, vol. 53, no. 10, pp. 31353141, 2005.

[28] S. Bastioli, "Nonresonating mode waveguide filters," IEEE Microwave Magazine, vol. 12, no. 6, pp. 77-86, 2011.

[29] C. Tomassoni and R. Sorrentino, "A new class of pseudoelliptic waveguide filters using dual-post resonators," IEEE Transactions on Microwave Theory and Techniques, vol. 61, no. 6, pp. 2332-2339, 2013.

[30] C. Tomassoni and R. Sorrentino, "A new class of pseudoelliptic waveguide filters using resonant posts," in Proceedings of the IEEE/MTT-S International Microwave Symposium Digest, pp. 1-3, Montreal, Canada, June 2012.

[31] P. Guan, A. T. Adams, Y. Leviatan, and J. Perini, Multiplepost inductive obstacles in rectangular waveguide," IEEE 
Transactions on Microwave Theory and Techniques, vol. 32, no. 4, pp. 365-373, 1984.

[32] N. Marcuvitz, "Waveguide handbook," in IET Electromagnetic Waves Series, vol. 21, pp. 257-273, McGraw-Hill, New York, NY, USA, 1986.

[33] G. L. Matthaei, L. Young, and E. M. T. Jones, Microwave Filters, Impedance-Matching Networks and Coupling Structures, McGraw-Hill, New York, NY, USA, 1964.

[34] U. Rosenberg and S. Amari, "A novel band-reject element for pseudoelliptic bandstop filters," IEEE Transactions on Microwave Theory and Techniques, vol. 55, no. 4, pp. 742-746, 2007.

[35] 3rd Generation Partnership Project; Technical Specification Group Radio Access Network; NR; User Equipment (UE) Radio Transmission and Reception; Part 1: Range 1 Standalone (release 15), 3GPP TS 38.101-1 V15.5.0, 2019.

[36] R. M. Borges, T. R. R. Marins, M. S. B. Cunha et al., "Integration of a GFDM-based 5G transceiver in a GPON using radio over fiber technology," Journal of Lightwave Technology, vol. 36, no. 19, pp. 4468-4477, 2018. 


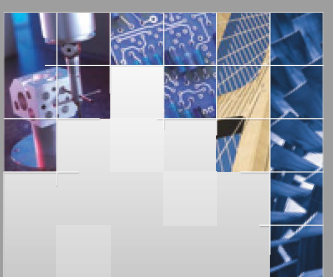

\section{Enfincering}
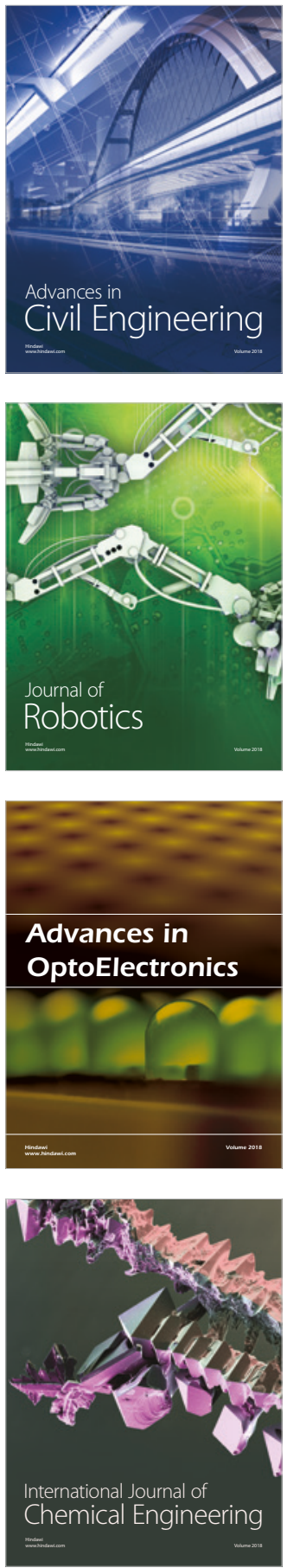

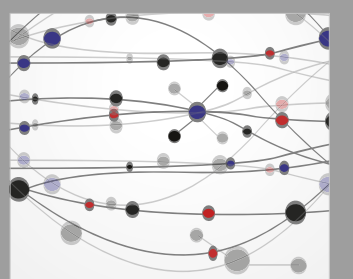

\section{Rotating \\ Machinery}

The Scientific World Journal

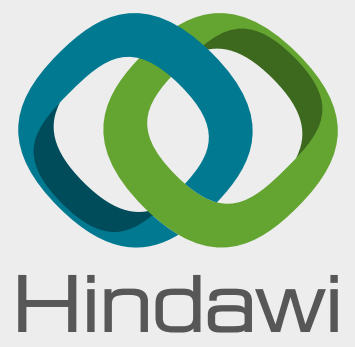

Submit your manuscripts at

www.hindawi.com
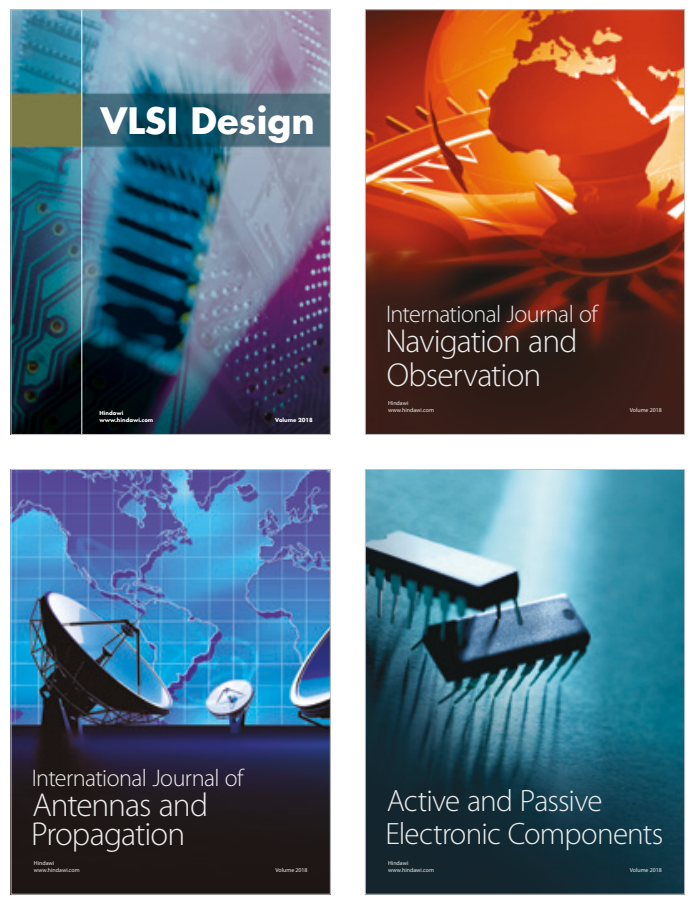
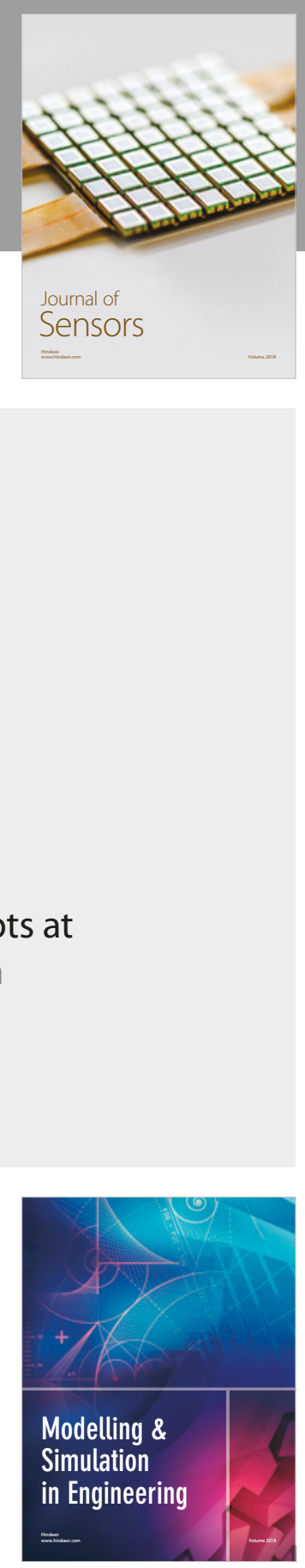

\section{Advances \\ Multimedia}
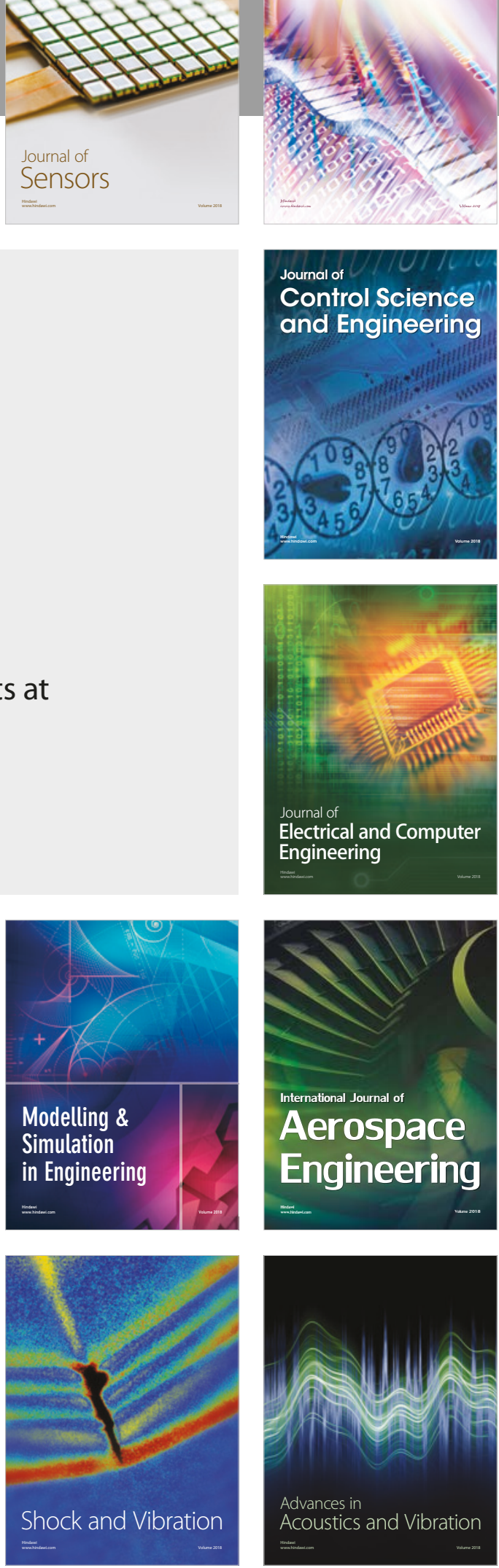